Попова А.Д.

\title{
ЭВОЛЮЦИЯ ОБЩЕСТВЕННОГО СОЗНАНИЯ КАК ФАКТОР ФОРМИРОВАНИЯ ГРАЖДАНСКОГО ОБЩЕСТВА
}

Аннотация: Статья анализирует проблему формирования гражданского сознания в России. Для развития гражданского общества характерно развитие рыночной экономики, правового государства, демократии, высокий уровень жизни людей, защита прав и свобод людей, а также состояние общественного сознания. В гражданском обществе не только государство защищает права и свободы людей, учитывает мнение людей при принятии решений, но и сами граждане уважают права друг друга, проявляют гражданскую активность, участвуя в выборах, в отправлении правосудия. Автор использует статистические сведения, результаты сочиологические опросов, исторические факты, которые выявляют особенности правовой и политической культуры россиян. Автор считает, что развитие гражданского сознания является важным фактором формирования гражданского общества в России. Им отмечается, что для ментальных установок характерно недоверие к власти, недопонимания важности уважения прав и свобод других людей, склонность к выбору принудительных мер для решения различных проблем. Россияне активно участвуют в различных социальных практиках, где государство не выступает в качестве посредника, но пассивны там, где надо взаимодействовать с властью.

Review: The author of the article analyzes the formation of civil consciousness in Russia. The process of development of a civil society is characterized by the development of market economy, legal state, democracy, high living standards, protection of rights and freedoms and the state of public consciousness. In a civil society not only the state protects the citizens' rights and freedoms and considers their opinion in the decision-making process but also citizens respect one another's rights and take an active part in the civil process, elections and execution of justice. Theauthorofthearticleusesstatistical information, results of sociological surveys and historical facts that help to define peculiarities of the legal and political culture of Russians. Intheauthor'sopinion, developmentofcivilconsciousnessis an important factor of formation of a civil society in Russia. The author underlines that Russians usually mistrust the government and disrespect the importance of rights and freedoms of other people. They also tend to use enforcement measures when solving their problems. Russians take an active part in different social practices where the government is not involved and they are rather passive in situations when they have to interact with the government.

Ключевые слова: гражданское сознание, ментальность, демократия, гражданское общество, гражданская активность, правовая культура, политическая культура, права и свободы, правовое государство, гражданское действие Keywords: civil consciousness, mentality, democracy, civil society, civil activity, legal culture, political culture, rights and freedoms, legal state, civic action.

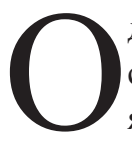

дним из наиболее активно употребляемых в современные дни политическим термином является понятие «гражданское общество». Именно формирование гражданского общества рассматривается как основополагающая цель развития российского общества.

По мнению автора под гражданским обществом следует понимать определенный характер взаимоотношений общества и государства, кото- рому присущи взаимная ответственность, высокий уровень защиты прав и свобод людей, возможность общества воздействовать на власть и отстаивать свои интересы.

Для гражданского общества характерен целый ряд признаков: 1) -уважение к личности и возможности реализации личного интереса, полное обеспечение прав и свобод людей; 2) - правовое государство; 3) демократический характер власти; 4) - развитое самоуправление; 


\section{Политика и общество 12 (108) • 2013}

5) - свободное формирование общественного мнения; 6) - возможность общества воздействовать на власть, посредством выборов, демонстраций, опротестований в суде решений власти; 7) - многоукладность экономики; 8) - высокий уровень жизни; 9) - состояние общественного сознания. Анализ современной ситуации в России показывает, что данные признаки развиты в России в различной степени. Одни элементы развиты в значительной степени, другие находятся только в стадии формирования. Наверное не вызовет сомнения, что в России уже сложилась рыночная экономика. На стадии формирования находятся такие признаки гражданского общества как возможность общества воздействовать на власть, демократический характер власти. В меньшей степени можно говорить о таком признаке как высокий уровень жизни общества. Пока мы не можем констатировать, что большинство россиян по уровню жизни относятся к среднему классу.

Также достаточно слабо выражен и последний признак - определенное состояние общественного сознания. Можно сказать, что для гражданского общества характерен высокий уровень развития гражданского сознания. Представляется важным выявить, что такое гражданское сознание и насколько оно развито в нашем обществе. Понимание этой проблемы позволяет осознать, насколько развито гражданское общество в нашей стране, и в какой области лежат проблемы по его развитию.

Гражданское сознание - понятие, которое только сейчас разрабатывается в науке. Профессор МГУ, д.и.н. А.Я. Лившин подчеркивает, что для гражданского сознания характерен ряд черт:

«1. Идею приоритета права, закона;

2. Гражданский гуманизм, отрицание насилия над личностью, неприятие ограничения ее прав и свобод;

3. Толерантность, признание возможности и полезности плюрализма, прав меньшинства и непривилегированных групп;

4. Идею о конституционных, правоосновных пределах властных действий и государственного насилия;

5. Психологическая готовность к инициативному гражданскому действию (в рамках закона) и понимание необходимости такого действия, отрицание социальной пассивности» ${ }^{1}$.

Если анализировать состояние общественного со-

1 Лившин А.Я. Общественные настроения в Советской России 1917-1929 гг. Автореф. дис... д-ра ист. наук. - М., 2004. C. 32 . знания в нашей стране по этим чертам, то можно отметить достаточно мозаичную картину. Принятие Конституции 1993 года создало правовую базу для формирования гражданского сознания, закрепив права и свободы граждан, плюрализм и политическое многообразие. Однако процесс формирования гражданского сознания процесс длительный и сложной.

Для российского общественного сознания характерен низкий уровень правовой культуры. Правовая неграмотность - явление практически повсеместное для российского общества. Даже среди наиболее образованной части молодежи - студентов - только единицы знакомы с текстом Конституции РФ. Даже самые простые вопросы по ее содержанию ставят молодых людей в тупик или порождают анекдотичные версии ответов. Так на вопрос, какие требования предъявляются к кандидату на пост Президента страны, вполне распространенным является утверждение о наличие ценза образованности (как правило, называют высшее юридическое образование). А одна студентка поразила автора статьи утверждением о том, что Президентом может стать только человек, имеющий знаменитых родственников. Представления о правах и свободах у граждан зачастую мифологизированы: граждане не знают о существующих правах и свободах или приписывают права и свободы, которые у них не существуют. И наиболее тревожным симптомом является нежелание граждан знакомиться с источниками права, читать Конституцию, законы, обращаться за помощью к юристам.

При этом граждане не очень хорошо знают собственные права и свободы, и еще хуже осознают какие права и свободы есть у других людей. Для российского общества характерен коллективизм и ставка на насилие как на средство решения всех проблем. Насилие по всей день является традиционной чертой ментальности россиян. Она сформировалась за многие годы, а точнее за века недемократической государственной и политической традиции. Как до революции 1917 года, так и после нее власть активно применяла насилие и принуждение для решения самых разных проблем. Оно выступало в разной форме, не только в виде откровенных репрессий и преследования политических оппонентов. Например, принудительное обучение дворян за границей, практикуемое Петром I, тоже есть насилие. Поэтому идея насилия прочно вошла в сознание людей, россияне очень медленно осознают, что надо не просто знать свои права и свободы, но и уважать пра- 
ва и свободы другого человека. Не случайно письма во власть, которые направлялись Б.Н. Ельцину или другим политическим деятелям в разгар перестройки, когда казалось бы только о свободе все и говорили, просто переполнены идеями насилия и принуждения. Из всех предложений по решению проблем экономического и политического развития чаще всего звучат принудительные меры. В частности, заставить всех работать, а не создать систему стимулов: «В обществе все должны работать. За укрывательство тунеядцев несет ответственность лицо укрывавшее в виде штрафа 500 рублей» ${ }^{2}$. Подобные фразы есть во многих посланиях. Это же касается и духовной сферы. Гражданину не нравится балет, он пишет письмо Б.Н. Ельцину с требованием запретить показывать балет по телевизору, называя данный вид искусства источником разврата и ... рэкета. По сей день в ментальные установки еще не вошел принцип: «я не разделяю его позицию, не согласен с ним, но это его право так думать».

Наиболее сложным моментом становления гражданского сознания является формирование психологической готовности к гражданскому действию. Конституция Российской Федерации предусматривает большой ряд такого возможного инициативного действия: создание политической партии (ст. 30), проведение митингов, демонстраций (31), участие в выборах и в управлении государством (32), обращение в органы власти (33), прохождение срочной службы, участие в отправлении правосудия. Также такими гражданскими действиями может быть благотворительность, волонтерство.

В этом плане ситуация очень неоднозначна. Российский гражданин достаточно активен в кризисные минуты. Как правило, когда имеет место какое-то бедствие, то рядовые граждане проявляют себя с наилучшей стороны. Так в дни стихийных бедствий - наводнения на Дальнем Востоке, наводнения в Крымске, пожаров в Центральной России пострадавшие получали помощь не только от государственных органов. Добровольцы шли тушить пожары, строить дамбы, собирали вещи. Участие в общем деле проявлялось даже в такой форме как приготовление пищи для тех, кто строил дамбы: домохозяйки городов делали бутерброды, варили картошку и приносили к месту строительства дамбы.

Однако это касается ситуации когда речь идет о взаимодействии внутри общества, то есть взаимодей-

${ }^{2}$ ГАРФ. 644. Оп. 1. Д. 49. Л. 65. ствия по линии «гражданин-гражданин». Однако наше общество слабо проявляет гражданскую активность во взаимодействиях с властью. То есть если между гражданами стоит государство, то гражданская активность намного меньше.

Для российского сознания характерен не только низкий уровень правовой культуры, но и низкий уровень политической культуры, что выражается в политической индифферентности. В тоже время уже становится очевидным, что «для стабильного демократического правления недостаточно определенных политических и управленческих структур, для этого нужна еще и соответствующая политическая культура, без поддержки которой шансы демократической системы на успех невелики»³. По данным ВЦИОМ весной 2013 года об участии в общественно-политической жизни страны заявили 59\% опрошенных. Наиболее распространенной формой участия граждан в политической жизни страны является участие в выборах (48\%). Другие формы участие в митингах, написание петиций, обращений в органы власти - россиянам свойственны меньше. Меньше тех, кто принимал участие в проведении избирательной кампании (4\%), а также в митингах и демонстрациях (3\%), деятельности политических партий $(1 \%)^{4}$. Однако и участие в выборах тоже не охватывает многих граждан. В 1993 г. на избирательные участки пришли 54,8\% избирателей, в 1995 г. - уже 64,7\%, в 2000 г. на президентских выборах активность избирателей составила $68,8 \%{ }^{5}$. Однако эта тенденция роста политической активности на выборах затем пропала. В декабре 2011 г. в выборах депутатов Государственной Думы приняли участие 59\% избирателей, в выборах Президента в марте 2012 г. - 65,3\% избирателей ${ }^{6}$. Наиболее распространенными аргументами, почему люди от-

\footnotetext{
${ }^{3}$ Омельченко Н.А., Гимазова Ю.В. О демократическом идолопоклонничестве, химерах русского политического либерализма и демократии в России // NB: Проблемы общества и политики. - 2013. - №9. - C. 153 - 182. URL: http://www.enotabene.ru/pr/article_9254.html.

${ }^{4}$ Официальный сайт ВЦИОМ // Режим доступа: http://wciom. ru/index.php?id=459\&uid=113269 Время доступа: 26.10.2013.

${ }^{5}$ Исаев Б.И., Баранов Н.А. Политические отношения и политический процесс в современной России. $\square$ СПб., 2008. - C. 291.

${ }^{6}$ Официальный сайт ЦИК РФ //Режим доступа: http://www. cikrf.ru/law/decree_of_cec/2012/03/07/Zp12893.html Время доступа: 29.10.2013.
} 


\section{Политика и общество 12 (108) • 2013}

казываются идти на выборы, является недоверие к чистоте выборов, ссылка как на мнимые, так и на реальные нарушения.

Прохождение срочной службы в армии часто рассматривается не как почетная обязанность, а как неприятная повинность. В среде молодых людей нередко можно услышать, что идти в амию - это значит терять год (ранее два). Причем службу в армии не связывают с идеями служения обществу, своей семье, а рассматривают как незаслуженные поползновения на личные планы со стороны государства. Также крайне неохотно граждане сотрудничают с правоохранительными органами, становятся присяжными заседателями. Перспектива помочь сотрудникам полиции прилива гражданской активности не вызывает. По данным ВЦИОМ только 46\% опрошенных сказали, что при необходимости готовы выполнить роль понятого ${ }^{7}$. С ситуацией, когда заседание суда не может начаться из-за недостаточной явки граждан для отбора в присяжные, столкнулись многие суды. Сотрудники Московского областного суда в 2003 году отмечали, что многие вызванные в суд в качестве присяжных граждане с ходу заявляли: «Где у вас тут штраф надо оплатить за отказ в участие в заседании? Я готов!» ${ }^{8}$. Как показал опрос, проведенный автором в 2005 году, граждане очень настороженно относятся к обязанности быть присяжным. Однозначно готовы были к выполнению такой обязанности, т.е. выбрали ответ «Да», только 17,2\% респондентов. 33,5\% выбрали ответ «Скорее да, чем нет» ${ }^{9}$.

В небольшой, но в достаточно оживленной виртуальной дискуссии по поводу суда присяжных, которая по инициативе автора статьи имела место в сентябре 2013 года на одном из Интернет-форуме, обсуждался вопрос, что будут делать участники форума, если получат повестку, приглашающую их в суд в качестве присяжных. Только несколько человек написали, что не будут игнорировать повестку. Тех, кто решительно отказался, было больше. В частности, писали следующие вещи: «В урну эту грязную бумажку. Такого удовольствия даром не надо. Если бы стали допекать - ответила бы, что не верю в правосудие, полиции и

\footnotetext{
${ }^{7}$ Официальный сайт ВЦИОМ // Режим доступа: http://wciom. ru/index.php?id=459\&uid=113269 Время доступа: 26.10 .2013

${ }^{8}$ Григорьева Е., Ратиани Н. Посаженные отцы. И матери // Известия. - 2003. - 23 января. - С. 7.

${ }^{9}$ Попова А.Д. Суд присяжных в зеркале общественного мнения //Социологические исследования. - 2007. - № 3. - С. 100.
}

юстиции не доверяю совсем» или «Буду искать всяческие поводы, чтоб откосить».

Достаточно показательны мотивы, которыми люди объяснили, свое нежелание идти в суд. Весьма распространенным является опасение мести со стороны подельников или родственников подсудимых: «Конечно, не имею никакого желания участвовать в этом, главным образом из-за страха за свою безопасность и недоверия к судебной системе РФ в целом». Однако также упоминалось нежелание тратить свое время: «Работа, некогда по судам иляться», «Хорошая темка для переписи бездельников». Также люди опасаются, что потеряют уважение знакомых или соседей, что проблемы возникнут дома и на работе: «А ещеё от соседей. Косо смотреть будут. И на работе». Больше всего поразили ссылки на рутинность процесса: «Это жуткая рутина и скукота, а не экин. Люди видать насмотрелись «Часов суда» всяких» или «нельзя болеть, пропускать, забивать на заседаниях. Пользоваться телефоном, выходить из зала» ${ }^{10}$.

Отмечу, что данная дискуссия была организована на своеобычном форуме: на нем общаются научные работники, преподаватели высших учебных заведений, сотрудники научно-исследовательских учреждений, аспиранты, профессора, т.е. интеллектуальная элита общества. То есть те, кто по идее должны быть в авангарде гражданской активности. Без гражданской позиции именно интеллигенции модернизация не возможна ${ }^{11}$. Можно отметить, что аналогичная ситуация имела место и до революции. Представители привилегированных и образованных слоев не особо стремились попасть в присяжные. В ход шли самые различные уловки: представлялись подложные свидетельства о болезни, подкупался адвокат, чтобы он отводил данного человека ${ }^{12}$. Профессор А.А. Демичев подчеркивает, что среди присяжных доля крестьян была очень значительна ${ }^{13}$. Низкий уровень гражданской активности в современные дни проявляется мно-

\footnotetext{
10 Форум портала аспирантов // Режим доступа: http://www. aspirantura.spb.ru/forum/showthread.php?t=11922\&highlight $=\% \mathrm{~F} 1 \% \mathrm{~F} 3 \% \mathrm{E} 4+\% \mathrm{EF} \% \mathrm{~F} 0 \% \mathrm{E} 8 \% \mathrm{~F} 1 \% \mathrm{FF} \% \mathrm{E} 6 \% \mathrm{ED} \% \mathrm{FB} \% \mathrm{~F} 5$ Время доступа: 26.10.2013.

${ }^{11}$ Щупленков О.В., Щупленков Н.О. Социальная роль интеллигенции в формировании гражданского общества // NB: Проблемы общества и политики. - 2013. - №7. - С. 13 - 72. URL: http://www.e-notabene.ru/pr/article_821.html

${ }^{12}$ Б.а. Дело. - 1868. - № 5. - С. 105.

13 Демичев А.А. История суда присяжных в дореволюционной России (1864-1917 гг.). М., 2007. - С. 296.
} 
гопланово: сами граждане не желают быть присяжными, но также и их руководители часто подталкивают подчиненных, чтобы они заявили самоотвод. Не случайно чаще всего самоотвод заявляют именно те граждане, которые в наибольшей степени подходят для этой роли: образованные, активные. Их деловые качества ценны на работе, поэтому если они даже и проявят желание занять место на скамье присяжных, то ему может помешать начальство. Формально присяжного нельзя уволить или перевести на другую должность, но есть много других способов воздействовать на слишком активного гражданина: лишить премии, отказать/послать в командировку. Поэтому судьям приходиться даже звонить в отделы кадров и убеждать отпустить ценного сотрудника на заседания суда ${ }^{14}$.

Можно сказать, что сознание россиян в основном носит не гражданский, а общинный характер, то есть люди готовы к сотрудничеству, но между собой, но не с властью. Власть пока воспринимается скорее как противник, надзиратель, но не партнер или посредник. Пока для российской ментальности характерно гордиться несоблюдением норм, установленных государством, или помогать друг другу их избегать (не платить налоги, сигнализировать о присутствие постового ГИББД). Более того, характерно не только недоверие, но неверие в способность государства что-то изменить, улучшить жизнь граждан. Не случайно в современном искусстве так популярен образ борцов за справедливость, которые действуют не в союзе с государством, а вопреки ему. В частности, в сериалах «Меч», «Пятницкий» показывают деятельность подпольных групп, осуществляющих карательные акции против криминального элемента. Примечательно, что в обоих фильмах членами этих подпольных групп являются действующие или бывшие сотрудники правоохранительных органов (полиции, прокуратуры), то есть даже они не верят в возможность законным способом покарать преступление.

Даже сталкиваясь с нарушением своих прав, граждане далеко не всегда решаются на конкретные действия: то есть на обращение в правоохранительные органы, заявления в органы исполнительной власти. Например, говоря о мнимых или даже реальных нарушениях в ходе предвыборной компании, граждане часто ограничиваются обсуждением на кухне, избегают писать официальные заявления. Возмущаясь нарушением своих прав, граждане словно ждут, что поя-

${ }^{14}$ Григорьева Е., Ратиани Н. Посаженные отцы. И матери // Известия. - 2003. - 23 января. - С. 7. вится некая сила, которая за них все сделает, чтобы нарушенное право было восстановлено. Необходимые в этом плане шаги (обращение в суд, сбор доказательств) оцениваются как волокита.

Таким образом, общественное сознание в настоящее время не достаточно развито, что тормозит развитие гражданского общества. Во многом это связано с особенностями российского общественного сознания. Оно, фактически, до сих пор носит общинный характер. Поэтому гражданская активность в виде помощи таким же людям как ты сам напрямую через различные формы социальных практик - от сбора пожертвований до участия в тушении пожаров - легко ложится на сознание россиян. В то же время власть государства не воспринимается как союзник. Поэтому содействие общему делу, помощь другим людям в более опосредованной форме с участием государства отвергается. Люди просто не понимают, что выполняя роль понятого или присяжного они помогают не сколько государству, а конкретному человеку. Люди с готовностью высказывают претензии правоохранительным органам, но не понимают, что их участие в рассмотрение уголовных дел в качестве присяжного дает возможность повлиять на работу полиции или Следственного комитета. В этом плане гражданское общество для россиян пока выступает в роли праздничного блюда, заказанное в ресторане, которое должно быть готовым преподнесено к столу. Его можно снисходительно попробовать, покритиковать и отправить на кухню с требованием дожарить или досолить. Однако гражданское общество может появиться только как результат совместных усилий общества и государства. Поэтому для углубления процесса развития институтов гражданского общества необходимо всячески содействовать развитию гражданского сознания. В этот процесс должны быть включены самые различные структуры: от школ и вузов, до средств массовой информации.

\section{Библиография:}

1. Лившин А.Я. Общественные настроения в Советской России 1917-1929 гг. Автореф. дис... д-ра ист. наук. - М., 2004.

2. Исаев Б.И., Баранов Н.А. Политические отношения и политический процесс в современной России. СПб., 2008.

3. Григорьева Е., Ратиани Н. Посаженные отцы. И матери // Известия. - 2003. - 23 января. 


\section{Политика и общество 12 (108) • 2013}

4. Попова А.Д. Суд присяжных в зеркале общественного мнения //Социологические исследования. - 2007. - № 3.

5. Демичев А.А. История суда присяжных в дореволюционной России (1864-1917 гг.). М., 2007.

6. Щупленков О.В., Щупленков Н.О. Трансформация власти в процессе построения гражданского общества в России // NB: Проблемы общества и политики. - 2013. - 9. - C. 20 - 88. URL: http:// www.e-notabene.ru/pr/article_9053.html

7. М. В. Михайлов Политика государства в сфере образования и становление гражданского общества в России // Политика и общество. - 2011. 7. - C. $4-11$.

\section{References (transliteration):}

1. Livshin A.Ya. Obshchestvennye nastroeniya v Sovetskoi Rossii 1917-1929 gg. Avtoref. dis... d-ra ist. nauk. - M., 2004.
2. Isaev B.I., Baranov N.A. Politicheskie otnosheniya i politicheskii protsess $\mathrm{V}$ sovremennoi Rossii. SPb., 2008.

3. Grigor'eva E., Ratiani N. Posazhennye ottsy. I materi // Izvestiya. - 2003. - 23 yanvarya.

4. Popova A.D. Sud prisyazhnykh v zerkale obshchestvennogo mneniya //Sotsiologicheskie issledovaniya. - 2007. - № 3 .

5. Demichev A.A. Istoriya suda prisyazhnykh $\mathrm{v}$ dorevolyutsionnoi Rossii (1864-1917 gg.). M., 2007.

6. Shchuplenkov O.V., Shchuplenkov N.O. Transformatsiya vlasti $\mathrm{v}$ protsesse postroeniya grazhdanskogo obshchestva v Rossii // NB: Problemy obshchestva i politiki. - 2013. - 9. - C. 20 - 88. URL: http://www.e-notabene.ru/pr/article_9053.html

7. M. V. Mikhailov Politika gosudarstva v sfere obrazovaniya i stanovlenie grazhdanskogo obshchestva v Rossii // Politika i obshchestvo. 2011. - 7. - C. $4-11$. 